\title{
Research on Natural Resources: The Quest for Integration Revisited
}

The dysfunctional use of resources in modern societies arises from increasing/y fragmented ways of understanding natural resources. Consequently, there have been repeated calls for integrative knowledge production, and various approaches to integration have been proposed, including such as interdisciplinary or transdisciplinary resource research and integrated resource

Basil Bornemann, Andreas Bernasconi, Olivier Ejderyan, Franziska Schmid, Patrick Wäger, Claudia Zingerli management. The conceptual space proposed here can be applied as a tool for imagining and designing new approaches, methods, and research techniques toward a more reflexive understanding of integration-oriented research on natural resources.

Research on Natural Resources: The Quest for Integration Revisited | GAIA 26/1 (2017): 16-21

Keywords: co-production, integrative research, interdisciplinarity, natural resources, transdisciplinarity

$\mathrm{N}$ atural resources, including water, soil, forests, game species, mined raw materials, and wind, are persistent points of reference for environmental science, discourse, and practice. Whether viewed from the perspective of ecological modernization, sustainable development, or the more recent idea of the Anthropocene (Hall et al. 2015), modern societies are blamed for undermining their natural resource base, thereby creating the risk of severe consequences for ecological integrity and societal welfare. Myopic economic interests and growth imperatives are not the only factors responsible for the dysfunctional or harmful patterns of resource use prevalent today. Rather, these patterns are also seen as emerging from our increasingly fragmented ways of knowing about natural resources. Consequently, there have been repeat-

Contact: Dr. Basil Bornemann | University of Basel | Department of Social Sciences | Sustainability Research | Bernoullistr. 14/16 | 4056 Basel | Tel.: +41612070428 | Switzerland | E-Mail: basil.bornemann@unibas.ch

Dr. Andreas Bernasconi | Pan Bern AG | Bern | Switzerland | E-Mail: andreas.bernasconi@panbern.ch

Dr. Olivier Ejderyan | ETH Zurich | Swiss Competence Center for Energy Research - Supply of Electricity | Zurich | Switzerland |

E-Mail: olivier.ejderyan@usys.ethz.ch

Dr. Franziska Schmid | RisikoWissen | Bern | Switzerland |

E-Mail: franziska.schmid@risikowissen.ch

Dr. Patrick Wäger | Empa, Technology \& Society Laboratory | St. Gallen | Switzerland | E-Mail: patrick.waeger@empa.ch

Dr. Claudia Zingerli | Swiss National Science Foundation | Bern | Switzerland | E-Mail: claudia.zingerli@snf.ch

(C) 2017 B. Bornemann et al.; licensee oekom verlag. This is an Open Access article distributed under the terms of the Creative Commons Attribution License (http://creativecommons.org/licenses/by/3.0), which permits unrestricted use, distribution, and reproduction in any medium, provided the original work is properly cited. ed calls for integrative knowledge production with regard to natural resources. These calls are reflected in approaches such as interdisciplinary or transdisciplinary resource research and integrated resource management.

In the present essay, we aim to shed new light on the quest for integration in natural resources research. More specifically, we provide some reflections on what integration-oriented research on natural resources could mean. For this purpose, we first offer an interpretation of the basic problematic against which demands for integration in natural resources research arise, namely the fragmentation of epistemic-practical resource regimes. Second, we map basic understandings of natural resources, research, and integration to open up a conceptual space for thinking about and doing integration-oriented research on natural resources. Third, on this basis, we reflect on existing interdisciplinary and transdisciplinary research on natural resources, as well as on integrated resource management, to consider how the challenge of integration is framed in dominant approaches of resource-related knowledge production. Finally, we sketch some ideas with regard to a more nuanced and reflected notion of integration-oriented research. Our essay is intended to encourage further discussion within the broad community of scholars and practitioners who recognize the need for further integration in research on natural resources.

\section{Problematic: Fragmented Epistemic-practical Regimes}

Although descriptions of modern societies tend to highlight nonmaterialist notions such as information, communication, or knowledge, natural resources remain of fundamental significance to many social processes (Sieferle et al. 2006, Kläy 2014). For ex- 
ample, natural resources are keys to economic development and human well-being; their degree of availability can propel or impede technological innovation and the development of cultural practices; societal power relations emerge and are transformed by natural resource issues (Forsyth 2003, Swyngedouw 2014); and as basic economic commodities, they trigger both the emergence and resolution of social conflicts (Mason et al. 2016).

The ubiquity of natural resources has implications for how contemporary societies deal with them. Given the ever-increasing differentiation of modern societies into multiple spheres of action with specific rationalities, highly fragmented practices of dealing with natural resources have emerged (figure 1). For example, a certain natural resource stock, such as a forest, is often managed according to a highly specific economic purpose while disregarding the implications of that management for other potential uses such as recreational activities. Moreover, various interlinked resource stocks are viewed and treated in relative isolation from each other. For example, fish stocks in a river are usually managed by a different institution from the one responsible for managing the watershed.

This widespread pattern of fragmented resource practices tends to be reproduced in current research on natural resources. Different epistemic fields (i.e., the natural sciences, humanities, and social sciences) as well as various disciplines within each field em- phasize different aspects of natural resources and related practices. In doing so, they have created highly specialized knowledge strands that are minimally related to each other. As this form of knowledge production also informs resource-related practices and triggers their fragmentation, we can speak of a fragmented epistemicpractical regime related to natural resources.

For quite some time now, this regime has been dysfunctional, in that it has produced negative side effects and second-order problems. For example, the use of a particular resource in multiple domains has propelled the emergence of resource conflicts, some of which are undermining societal harmony. ${ }^{1}$ This problematic has given rise, in both science and practice, to efforts to deal with resource management in more integrative ways (Murugesu et al. 2012, Waterton et al. 2015, EC 2008). In resource-related research, this turn toward integration is mostly reflected in general approaches such as interdisciplinarity or transdisciplinarity. However, what these approaches can offer with regard to improving the fragmented resource regime remains unclear.

1 For instance, in industrialized countries the use of landscape resources by new inhabitants of suburban and rural communities can lead to conflicts. Ecological values and recreational use might lead newcomers to support the restoration of streams used for agricultural drainage (Ejderyan 2014).

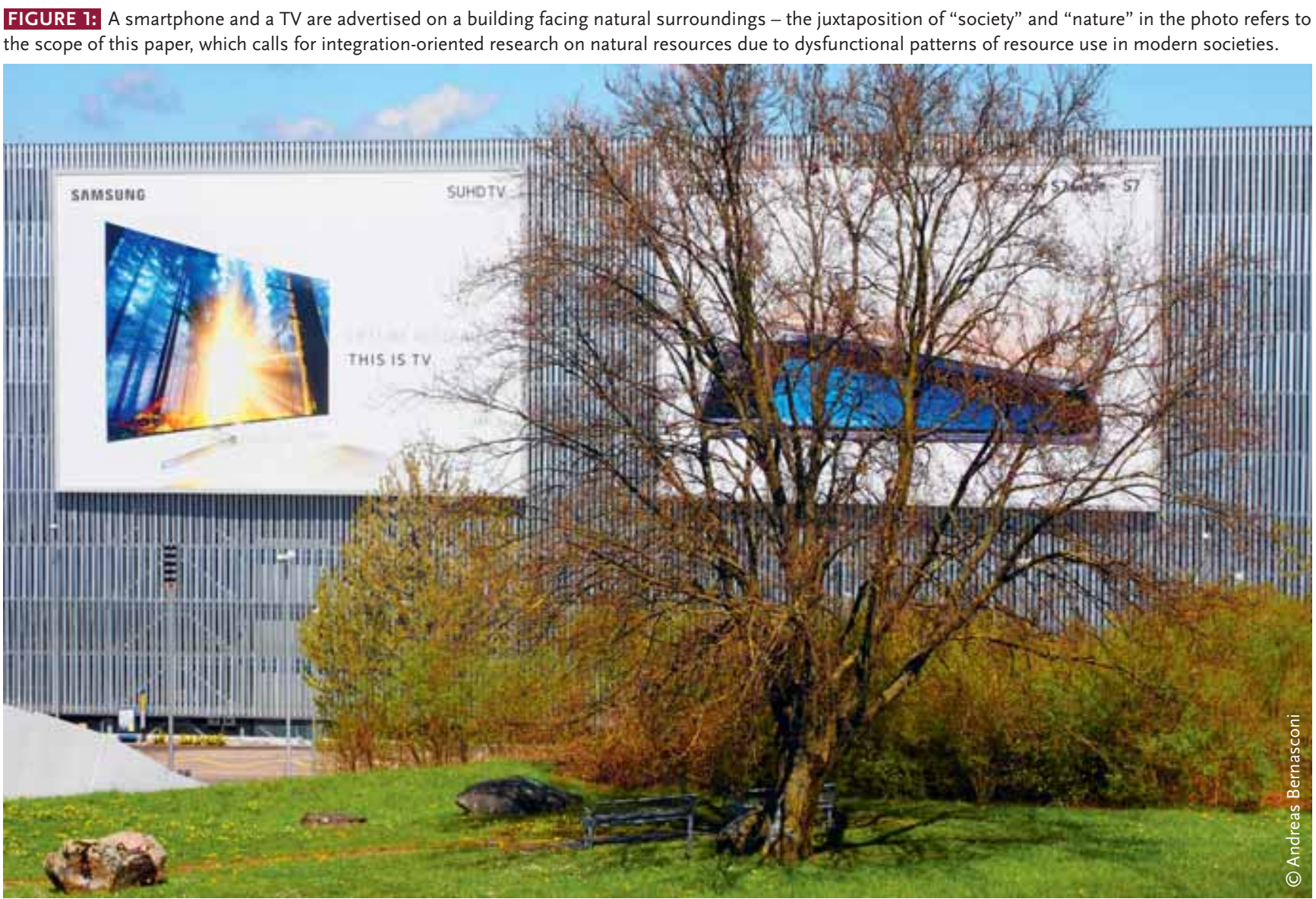




\section{Concepts: Natural Resources, Research, and Integration}

To address this question, we will elaborate on the meaning of natural resources, research, and integration in order to develop a conceptual space that provides a basis for thinking about and doing integration in research on natural resources.

\section{Natural Resources}

A resource is something that holds meaning and value for human beings. Resources are not universal givens, but "products of biological, ecological, or geological processes that satisfy human wants" (Bridge 2009, p. 261). This means that resources are constituted in relation to human actions (cf. Johnston et al. 1994, Wiesmann 1995). This relational understanding implies that the qualifier natural is not meant to naturalize resources, that is, to detach them from their embeddedness in human actions. Rather, the term specifies the presence of some physical matter that forms the essential material dimension of natural resources - in contrast, for example, to cultural, economic, and human resources. However, to qualify as a natural resource, this physical matter has to undergo some form of human meaning-making; that is, it must be identified and valued as a resource useful to humans. This act of interpretation entangles the physical matter with a symbolic dimension consisting of a set of cognitive and normative ideas. The meaning-making process, in turn, takes place in social settings, in which individuals and groups struggle about the meaning of resources in interactive processes. As a result, a natural resource is a construct that connects a matter-based material dimension with a meaning-based symbolic dimension and an interaction-based social dimension (cf. Blaikie 1999, who embodies a soft social-constructivist stance).

\section{Research}

Whereas natural resources refer to a multi-dimensional thing, the term research signals a certain way of approaching a given object. Most generally, research pertains to either a process or a result of knowledge production. With regard to the overall purpose of research, one can identify at least two basic paradigms with many shades in between: a paradigm of truth-oriented research to fill existing knowledge gaps (knowledge-oriented research) and a tradition of use-oriented knowledge production to guide action and social improvement (action-oriented research) (Checkland and Holwell 1998). Whereas the former is commonly associated with academic science organized into disciplines that draw on distinct epistemologies and methodologies, the latter also involves nonacademic experts, societal actors, and citizens who engage in practical problem solving.

\section{Integration}

According to a generic analytical understanding, integration refers to the relating of at least two dispersed parts (integrands) in such a way that they together constitute a third (integral whole) (cf. Bornemann 2014). Such an abstract understanding raises two basic conceptual questions that must be answered when we speak of integration: what (i.e., what objects) is related and how (i.e., in what mode) (Bornemann 2014). In view of the abundance of potential integration objects, the what question can hardly be answered generally. However, given our specific topic of interest, integration can refer to either the natural resources themselves or to research. In the former case, integration entails adopting a view that highlights the links between different types and/or dimensions of natural resources in more complex assemblages. The latter form of integration focuses on relating various research perspectives, such as action-oriented and knowledge-oriented research.

The how question allows for additional conceptual differentiations with regard to a number of ideal-typical structural ("integrated"), functional ("integrative") and procedural ("integrating") modes of integration (see Bornemann 2014, pp. $87 \mathrm{ff}$.). The distinction between symmetrical and asymmetrical modes of integratedness, for example, refers to the relative weight of integrands (e.g., layers or perspectives) in an integral whole; the differentiation between strong and weak integration, meanwhile, denotes different degrees of autonomy of the integrands within the integral whole. The presence of a multiplicity of possible modes of integration carries with it the critical implication that integration is neither self-explanatory nor unambiguous; rather, one needs to specify and justify the particular mode(s) of integration when one applies the concept.

\section{Integration-oriented Knowledge Production}

Drawing on this conceptual space, we will now look at three dominant approaches to integration-oriented knowledge production in the field of natural resources: 1 . interdisciplinarity, 2. transdisciplinarity, and 3. integrated resource management. More specifically, we will discuss how these approaches frame the endeavors of integration-oriented research. ${ }^{2}$

\section{Interdisciplinarity (ID)}

In the last twenty years, ID has become a major orientation fostering innovation and complex problem solving in our highly differentiated and specialized system of research. With its aim of bringing together various disciplines to tackle complex phenomena, ID has a clear ambition of achieving integration.

Natural resources have long been among the broad spectrum of objects considered for ID (cf. Heberlein 1988). While the natural sciences enable our understanding of the material layer of natural resources, the humanities illuminate the symbolic layer by offering, for example, historical knowledge about the contextual meaning of natural resources. Moreover, social scientists provide

\footnotetext{
2 Our intention is not to exhaustively discuss the theoretical and practical breadth of each approach; rather, we refer to prevailing understandings and practices from our point of view as active researchers in the field.
} 
knowledge about the social interactions that form around natural resources.

However, ID comes with a clear focus on academic research. More specifically, it represents an answer to the ever-differentiating disciplinary specialization occurring within academia and therefore remains restricted to the academic sphere of knowledge production. Non-academic research practices that lie beyond the disciplinary organization of our contemporary system of scientific scholarship are also beyond the scope of ID.

Within its academically oriented framework, ID seems to feature the narrow integration of neighboring disciplines of "the same kind" - that is, disciplines of relative epistemological and methodological similarity - as the social sciences and the humanities are generally reluctant to engage in ID research on natural resources (Heberlein 1988, Schmid and Stauffacher 2013, Wäger et al. 2014). Where ID research does cut across the boundaries between these different ways of knowing, it tends to promote task sharing between the natural sciences, which reflect on problems and possible solutions, and the social sciences, which look at the extent of acceptance of potential solutions (Sievanen et al. 2012).

Finally, there is a tendency to consider the "inter" in ID as simply adding disciplines rather than thoroughly interrelating their efforts. This approach fosters the emergence of rather loosely related research clusters organized around and dominated by a disciplinary nucleus, resulting in a weak and asymmetric mode of integration. The multiple clusters produce separate sets of disciplinary knowledge on a common topic, which are integrated at the very end of a project, in a form of ex-post integration (cf. Whatmore 2009, Barry and Born 2013).

\section{Transdisciplinarity (TD)}

TD relates to a problem-oriented research approach that strives for co-production of knowledge by integrating different scientific disciplines and societal actors (Pohl 2008, Klein et al. 2001). From the outset, TD research has been described as representing an integrative approach with the vision of relating scientific and practical knowledge to generate more comprehensive, more problemfitting, and more socially robust knowledge.

TD is characterized by a problem-oriented perspective. Although new discussions have emerged recently on the question of how problems are framed, TD has generally seemed to take a fairly objectivist approach to "real-world problems"; in other words, the problems are treated as given rather than as socially constructed. This emphasis on the material dimension of natural resources tends to disregard their relational character and their social and symbolic dimensions.

TD features an understanding of research as co-production of knowledge between science and practice. TD literature provides rich reflections on the different types of scientific and practical knowledge and how they can be related to cope with complex problems (Hirsch Hadorn et al. 2008). Moreover, the literature contains models of research processes as well as methods intended to facilitate the co-production of knowledge between science and practice (Lang et al. 2012, Wiesmann et al. 2011). This understanding of research forms the core of TD's notion of integration as a problem-oriented relating of scientific and practical knowledge. ${ }^{3}$

\section{Integrated Resource Management (IRM)}

IRM refers to a family of approaches that seek to overcome the fragmentation of resource systems by organizing resource-related management practices in an integrative manner. These approaches are manifested in several types of interventions, such as regional plans, monitoring systems, or projects dealing with a specific resource stock. The inclusion of multiple practices sometimes constitutes more comprehensive institutional resource regimes that shape the way in which resources are managed and used (cf. Kissling-Näf and Varone 2000, Knoepfel and Gerber 2008).

Natural resources are clearly at the core of IRM. IRM practices convey an understanding of natural resources as manageable stocks and thereby highlight their tangible material aspects. The actors involved in IRM as administrators and managers are primarily experts with a natural science background. Consequently, IRM sometimes tends to conceive of natural resources as material entities to be captured, monitored, and managed based on objective knowledge while disregarding their symbolic dimensions.

IRM represents the practice-oriented end of the range of integrative approaches described here. In fact, given its focus on action, some would question whether IRM should be considered a research approach at all. However, we argue that IRM involves research practices since it normally prescribes or assumes arrangements of knowledge management and production (such as problem analysis tools, scenario techniques, and monitoring systems). Despite this grounding in research functions, the knowledge produced within IRM is practically oriented, intended to guide action and interventions in resource systems so as to concretely affect material resource stocks and flows or land use activities.

Regarding the objects of integration, IRM refers to the relating of different kinds of objects such as sectoral problems, goals and means; actors with different backgrounds, rationalities, and interests; levels of action (local, regional, national, or global); and temporal scales (from short-term to long-term). These different objects correspond with a wide range of methods and planning tools that support the integration of knowledge and of conflicting interests or competing values, such as multi-criteria analysis, integrative planning procedures, or stakeholder involvement methods. Furthermore, regarding modes of integration, IRM seems to be based on the idea of balancing. Various accounts and knowledge elements related to different spheres of practice are supposed to be taken into account equally to form a coherently functioning IRM arrangement. Since in practice, however, the power of in-

\footnotetext{
3 Although the notion of co-production implies an understanding of integration as balancing, much of TD practice appears to be dominated by the academic side of the collaboration. This practice may derive from the fact that TD has its roots in academia and does not travel well across academic boundaries. TD projects are regularly initiated and organized by academics, as most funding schemes require academic partners to take the lead.
} 
TABLE 1: The table compares three approaches of knowledge production in the field of natural resources: interdisciplinarity, transdisciplinarity, and integrated resource management. They differ with regard to their conceptions of integration.

\begin{tabular}{llll}
\hline & natural resources & research & integration \\
\hline interdisciplinarity & multi-layered objects & science & homogeneous, weak, and asymmetrical integration of disciplines \\
\hline transdisciplinarity & complex problems & science-practice & asymmetrical integration of science and practice \\
\hline integrated resource management & manageable material stocks & practice & balancing, but erratic integration of diverse objects and practices \\
\hline
\end{tabular}

volved institutions (e.g., legal, political, or regulatory settings) and actors plays an important role in structuring how different knowledge elements are related within an IRM arrangement, integration becomes a rather erratic endeavor.

\section{Comparing the Three Approaches}

The three approaches imply different understandings of integration-oriented research on natural resources and offer different potential for tackling the problem of fragmented epistemic-practical resource regimes (table 1). ID seems most able to take account of the multi-layeredness of natural resources, whereas TD and IRM embody some biases toward materialist understandings. The approaches also differ with regard to their implicit conceptions of integration. ID aims to integrate scientific knowledge and focuses on relating the work of neighboring disciplines in a rather summative way. TD pursues the integration of scientific and practical knowledge in a somewhat asymmetrical fashion, with academia taking the lead. IRM aims to integrate various kinds of objects in a problem- and solution-oriented and balanced manner, but its form varies depending on the institutional and political power structures undergirding it.

\section{Perspectives}

Through this essay, we hope to revive the quest for integration in research on natural resources. For this purpose, we have interpreted the problematic that underlies repeated calls for integration in research on natural resources as consisting of fragmented epistemic-practical regimes. We revealed a plurality of possible ways of thinking about and doing integrative research on natural resources by mapping the relevant meanings of natural resources, research, and integration. Our discussion of three common approaches to integration-oriented natural resources research (TD, ID, and IRM) revealed that they imply different understandings of natural resources, represent different ideas of knowledge production, and come with different (implicit) conceptions of integration. What follows from these considerations for the future of integration-oriented research on natural resources?

First, we see good reasons for integration to become the default attitude toward and vanishing point for research on natural resources. Many of the critical issues facing us today, such as increasing urbanization leading to land use conflicts in and around large metropolitan areas, the rarefaction of raw materials due to increasing demand by industry, and variations in crop yields related to climate change, highlight the entanglement of various layers and types of natural resources - and the limitations of fragmented epistemic-practical regimes to address these issues.

Second, our reconstruction of three prominent approaches reminds us that there are multiple ways of thinking about and doing integration-oriented natural resources research. Each of these ways might be more or less adequate for a particular context or set of challenges. Therefore, we argue for a reflexive understanding - that is, an understanding that is intentionally aware of its own implications. Such a reflexive understanding would, for example, make use of different approaches that may be suitable for different practical problems of resource fragmentation.

Third, the conceptual space that we have proposed itself provides the ground for such a reflexive endeavor. For instance, it may help to capture the peculiarities of integration-oriented research approaches and, in this vein, might be extended to other approaches such as sustainability, transformative, or action research. In addition, the conceptual space may also be used on a methodological level to reflect on and sort out more specific research methods or techniques. For example, it may help in deciphering the implicit understandings and assumptions that underlie certain integration-oriented methods of system analysis, scenario techniques, or integrated assessments. This step may result in a more precise understanding of the particular potentials and limitations of these methods for integration-oriented natural resources research.

Fourth, this conceptual space, since it grasps and compiles relevant references for thinking about and doing integration-oriented research, can also be applied as a tool for imagining and designing new approaches, methods, and research techniques. It may also inspire the design of institutional framing conditions and research policies (e.g., funding schemes) specifically envisioned to advance integration in natural resources research and thereby lay the foundation for the emergence of less dysfunctional and harmful practices of dealing with natural resources.

This paper has emerged from discussions within the working group Integrative Research on Natural Resources of the Swiss Academic Society for Environmental Research and Ecology (saguf). The authors are indebted to Michael Stauffacher for critical comments on earlier versions of the paper, as well as to two anonymous reviewers whose comments helped to improve the paper. 


\section{References}

Barry, A., G. Born (Eds.). 2013. Interdisciplinarity. Reconfigurations of the social and natural sciences. London: Routledge.

Blaikie, P. 1999. Political ecology. Issues epistemology and analytical narrative. Zeitschrift für Wirtschaftsgeographie 43/3-4: 131-147.

Bornemann, B. 2014. Policy-Integration und Nachhaltigkeit: Integrative Politik in der Nachhaltigkeitsstrategie der deutschen Bundesregierung. Wiesbaden: Springer VS.

Bridge, G. 2009. Natural resources. In: International encyclopedia of human geography. Volume 7. Edited by R. Kitchin, N. Thrift. Amsterdam: Elsevier. 261-268.

Checkland, P., S. Holwell. 1998. Action research: Its nature and validity. Systemic Practice and Action Research 11/1: 9-21.

EC (European Commission). 2008. Integrating water policy: Linking all EU water legislation within a single framework. WISE note 9. http://ec.europa.eu/ environment/water/participation/pdf/waternotes/water_note9_other_ water_legislation.pdf (accessed February 8, 2017).

Ejderyan, O. 2014. Quels aménagements pour quelle nature? Hydrologie, patrimoine et biodiversité dans le projet de renaturation de la HauteSeymaz à Genève. In: Urbanités et biodiversité. Entre villes fertiles et campagnes urbaines, quelle place pour la biodiversité? Edited by V. Bradel. Saint-Etienne: Presses de l'Université de Saint-Etienne. 262-275.

Forsyth, T. 2003. Critical political ecology. The politics of environmental science. London: Routledge.

Hall, M., P. Forêt, C. Kueffer, A. Pouliot, C. Wiedmer. 2015. Seeing the environment through the humanities: A new window on grand societal challenges. GAIA 24/2: 134-136.

Heberlein, T. A. 1988. Improving interdisciplinary research: Integrating the social and natural sciences. Society and Natural Resources 1/1: 5-16.

Hirsch Hadorn, G. et al. (Eds.). 2008. Handbook of transdisciplinary research. Dordrecht: Springer.

Johnston, R. J., D. Gregory, D. M. Smith. 1994. The dictionary of human geography. Oxford, UK: Blackwell.

Kissling-Näf, I., F. Varone (Eds.). 2000. Institutionen für eine nachhaltige Ressourcennutzung. Innovative Steuerungsansätze. Chur, Zurich: Rüegger.

Kläy, A. 2014. Umgang mit erneuerbaren Ressourcen: Herausforderung Nachhaltigkeit. GAIA 23/4: 360-362.

Klein, J.T., W. Grossenbacher-Mansuy, R. Häberli, A. Bill, R.W. Scholz, M. M. Welti (Eds.). 2001. Transdisciplinarity: Joint problem solving among science, technology, and society: An effective way for managing complexity. Basel: Birkhäuser.

Knoepfel, P., J.-D. Gerber. 2008. Institutional landscape regimes. An approach to the resolution of landscape conflicts. Research Report NRP 48. Zurich: VDF Hochschulverlag.

Lang, D.J. et al. 2012. Transdisciplinary research in sustainability science: Practice, principles, and challenges. Sustainability Science 7/1: 25-43.

Mason, S., D. Sguaitamatti, M. del Pilar Ramirez Gröbli. 2016. Stepping stones to peace? Natural resource provisions in peace agreements. In: Governance, natural resources, and post-conflict peacebuilding. Edited by C. Bruch, C. Muffett, S. Nichols. London: Routledge. 71-120.

Murugesu, S., H. Savenije, G. Blöschl. 2012. Socio-hydrology: A new science of people and water. Hydrological Processes 26/8: 1270-1276.

Pohl, C. 2008. From science to policy through transdisciplinary research. Environmental Science and Policy 11/1: 46-53.

Schmid, F., M. Stauffacher. 2013. Nachhaltiger Umgang mit natürlichen Ressourcen - sozial- und geisteswissenschaftliche Forschungslandschaft der universitären Hochschulen der Schweiz. Bern: Schweizerische Akademie der Geistes- und Sozialwissenschaften.

Sieferle, R. P., F. Krausmann, H. Schandl, V. Winiwarter. 2006. Das Ende der Fläche: Zum gesellschaftlichen Stoffwechsel der Industrialisierung. Cologne: Böhlau.

Sievanen, L., L. M. Campbell, H. M. Leslie. 2012. Challenges to interdisciplinary research in ecosystem-based management. Conservation Biology 26/2: 315-323.

Swyngedouw, E. 2014. Social power and the urbanization of water: Flows of power. Oxford, UK: Oxford University Press.

Wäger, P., O. Ejderyan, F. Schmid, M. Stauffacher, C. Zingerli. 2014. The role of social sciences and humanities in integrative research on natural resources. GAIA 23/2: 142-144.

Waterton, C., S. C. Maberly, J. Tsouvalis, N. Watson, I. J. Winfield, L. R. Norton. 2015. Committing to place: The potential of open collaborations for trusted environmental governance. PLOS Biology 13/3: e1002081.
Whatmore, S. 2009. Mapping knowledge controversies: Science, democracy and the redistribution of expertise. Progress in Human Geography 33/5: 587-598.

Wiesmann, U. 1995. Nachhaltige Ressourcennutzung im regionalen Entwicklungskontext. Konzeptionelle Grundlagen zu deren Definition und Erfassung. Berichte zu Entwicklung und Umwelt 13. Bern: University of Bern.

Wiesmann, U., H. Hurni, C. Ott, C. Zingerli. 2011. Combining the concepts of transdisciplinarity and partnership in research for sustainable development. In: Research for sustainable development: Foundations, experiences, and perspectives. Edited by U. Wiesmann, H. Hurni. Bern: Geographica Bernensia. 43-70.

\section{Submitted October 6, 2016; revised version accepted February 8, 2017.}

\section{Basil Bornemann}

Born 1978 in Bad Säckingen, Germany. Diploma in environmental sciences, PhD in political science, Leuphana University of Lüneburg. Postdoc at Sustainability Research Group, University of Basel. Research interests: sustainability governance and democracy, food politics, sustainability science.

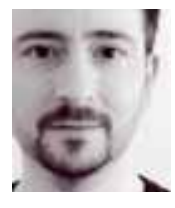

Andreas Bernasconi

Born 1960 in Bern, Switzerland. Diploma in forest engineering and PhD in forestry, ETH Zurich. Consultant in forest planning, sustainable forest management and urban forestry at Pan Bern AG. Research interests: forest resource and stake-

holder management and sustainability, forest education.

Olivier Ejderyan

Born 1977 in Solothurn, Switzerland. MA in geography and planning, University of Paris-Sorbonne. PhD in geography, University of Zurich. Senior lecturer at the Swiss Competence Center for Energy Research - Supply of Electricity, ETH Zurich. Current research on the politics of deep geothermal energy.

Franziska Schmid

Born 1974 in Bern, Switzerland. Diploma and PhD in geography, University of Bern. Former scientific collaborator at academia and federal administration. Now director of private company RisikoWissen dedicated at knowledge management

and synthesis work in the field of disaster risk reduction.
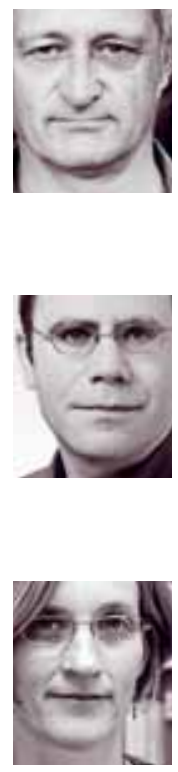

Patrick Wäger

Born 1963 in Basel, Switzerland. BA in philosophy and sociology, University of Zurich. MSc in chemistry and $\mathrm{PhD}$ in environmental sciences, ETH Zurich. Head of Technology \& Society Laboratory at Empa. Research interests: circular economy, critical raw materials, emerging technologies, societal metabolism, sustainability transitions. Member of GAIA's Scientific Advisory Board.

Claudia Zingerli

Born 1973 in Basel, Switzerland. MA in geography. PhD in development studies, University of East Anglia, UK. Scientific coordinator at Swiss National Science Foundation (SNSF). Research interests: politics of knowledge in international development, innovation, learning and co-creation in science-practice interfaces.
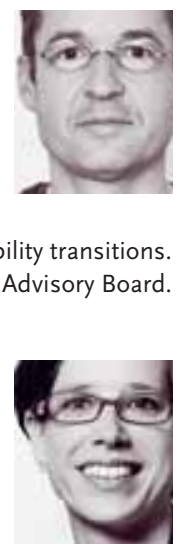